OPEN ACCESS

Edited by:

Qiuhua Liang,

Loughborough University,

United Kingdom

Reviewed by:

Albert Chen,

University of Exeter, United Kingdom

Guy Jean-Pierre Schumann,

University of Bristol, United Kingdom

*Correspondence:

James E. Ball

james.ball@uts.edu.au

Specialty section:

This article was submitted to Hydrosphere,

a section of the journal

Frontiers in Earth Science

Received: 14 January 2020

Accepted: 01 April 2020

Published: 28 April 2020

Citation:

Ball JE (2020) An Assessment of Continuous Modeling for Robust

Design Flood Estimation in Urban

Environments. Front. Earth Sci. 8:124.

doi: 10.3389/feart.2020.00124

\section{An Assessment of Continuous Modeling for Robust Design Flood Estimation in Urban Environments}

\author{
James E. Ball* \\ School of Civil and Environmental Engineering, University of Technology Sydney, Ultimo, NSW, Australia
}

Catchment management is a complex task that, over the past decade, has become increasingly important to urban communities. While there are many water related management issues, estimation of the magnitude and likelihood of flood events is one that remains a concern to many mangers of urban drainage systems. Data is an essential component of any approach for estimation of the magnitude and likelihood of design flood characteristics. This data can be obtained from catchment monitoring or catchment modeling with these data sources being complementary rather than competitive. However, the absence of monitored data in urban environments has resulted in the data being obtained predominantly from the use of catchment modeling. Numerous alternative approaches for catchment modeling have been developed; these approaches can be categorized as either single event or continuous models. The philosophical basis behind the use of a continuous modeling approach is the concept that the model predictions will replicate the data that would have been recorded if catchment monitoring were to be undertaken at that location and for the modeled catchment conditions. When using this philosophy, a modeler must determine when the predicted data suitably replicates the true data. Presented herein is an analysis of continuous and event modeling undertaken for design flood estimation in an urban catchment located in Sydney, Australia where monitored data is available to assess the utility of the catchment model. It will be shown that frequency analysis of the predicted flows from the continuous model more closely resemble the frequency analysis of the recorded data.

Keywords: floods, urban, SWMM, risk, model

\section{INTRODUCTION}

Catchment management is a complex task that, over the past decade, has become increasingly important to the community. This is particularly the case for urban environments. Of the many catchment management issues, estimation of the magnitude and likelihood of flood events is one that remains an issue in many urban environments. There are many different issues requiring design flood estimation; see, for example, Audisio and Turconi (2011), Hettiarachchi et al. (2018), and Andimuthu et al. (2019) who present different aspects of the need to estimate design floods in urban environments. As a consequence, design flood estimation remains a significant problem for management of many urban catchments. 
While the flood characteristics important for management of a drainage system will vary between problems, Ball (2014) suggests that, typically, the flood characteristic of concern will be one of the following:

- Flood flow rate - the peak flow rate of the flood hydrograph is a common design flood hydrograph characteristic used, for example, to size drainage system components;

- Flood level - the peak flood level during a flood hydrograph is a common design flood hydrograph characteristic used, for example, in setting minimum floor levels;

- Flood rate of rise - this design flood characteristic is a concern when planning for evacuation;

- Flood volume - this design flood characteristic becomes a concern when storage of the design flood is being considered as part of a flood management system; or

- System failure - the usual design flood problem is located at a single point. There are numerous design problems, however, where the critical concern is prediction of system failure. Examples of these problems include urban drainage systems and transportation routes with multiple cross drainage structures.

In Australia, a risk management approach provides the foundation for flood management (Ball et al., 2016). When a risk management approach is used, it is necessary to estimate both the magnitude of the hazard and the likelihood of the hazard. In other words, there is a need to consider the relationship between the magnitude and the exceedance probability of a design flood characteristic. An example of this relationship is shown in Figure 1.

Arising from the need for predictions of the relationship between flood hazard and its likelihood, a number of alternative approaches have been developed. Smithers (2012), discusses these approaches and categorizes the approaches considered as being either "analysis of streamflow data" or "rainfall based"; herein, similar categories are used although they are referred to as "catchment monitoring approaches" and "catchment modeling approaches". In reviewing rainfall-based approaches, Smithers (2012) notes that continuous simulation approaches have been

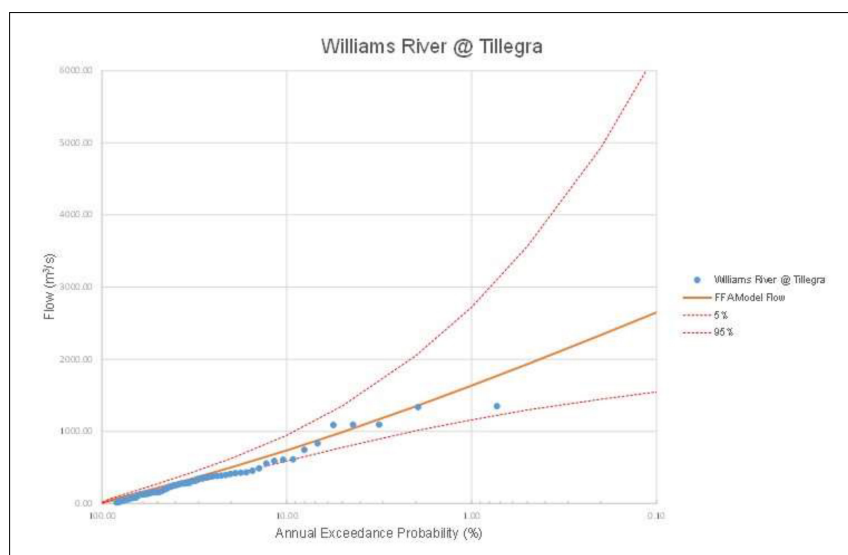

FIGURE 1 | Relationship between flood hazard and likelihood. proposed to overcome inherent biases introduced through use of single event approaches.

While estimation of the relationship between the magnitude and the likelihood, or probability, of a flood hazard can be achieved through alternative approaches, a fundamental need for all approaches is the availability of suitable data. This data can be obtained from catchment monitoring or catchment modeling. The aim of a catchment monitoring is the collection of data about the desired flood characteristics within the catchment over multiple storm events. Typically, the data obtained will include time-series data at various time scales and spatial data, during and post events, of differing resolutions. To obtain relevant information about the flood risk within the catchment, as explained by Ball (2018) this collected data is mined to extract relevant information about the relationship between the magnitude and the likelihood of the flood hazard.

The alternative approach to catchment monitoring is catchment modeling. Conceptually, the aim of catchment modeling is to generate data that would have been recorded if catchment monitoring had been in place for the event, or sequence of events, at the locations being considered. Hence, the generated data should have the same characteristics as the historical data that could have been monitored at the site or sites of interest. Where changes in catchment management, e.g., land-use, or changes in climatic conditions are to be considered, catchment modeling techniques are required; catchment monitoring approaches can be used only when a physical catchment exists. Finally, similar to data obtained from catchment monitoring, mining of the data obtained from catchment modeling is required to extract relevant information about the likelihood of a flood hazard.

As implied in the previous discussion, catchment modeling can be used to provide data at locations remote from monitoring locations. The converse is also valid; catchment monitoring can be used to validate predictions obtained from catchment modeling. Hence, effective flood management for a catchment requires data from both catchment monitoring and catchment modeling programs. Presented herein will be a discussion of the use of monitored and modeled data in the estimation of the flood risk in the Powells Creek catchment located in the inner west suburbs of Sydney, Australia. Of particular interest is the viability of predicting flood risk from analysis of data generated through continuous simulation of catchment processes.

\section{POWELLS CREEK CATCHMENT}

\section{Catchment Description}

The Powells Creek catchment, sometimes referred to as the Strathfield catchment, is an 841 ha catchment situated $10 \mathrm{~km}$ west of Sydney's central business district. The location of this catchment is shown in Figure 2. The catchment lies within the Sydney suburbs of Homebush West, North Strathfield, Rookwood and Strathfield, and is administered by the local government areas of Strathfield, Canada Bay and Auburn. The drainage network comprises a closed piped system that opens out to a lined channel and then into the Parramatta River. The 


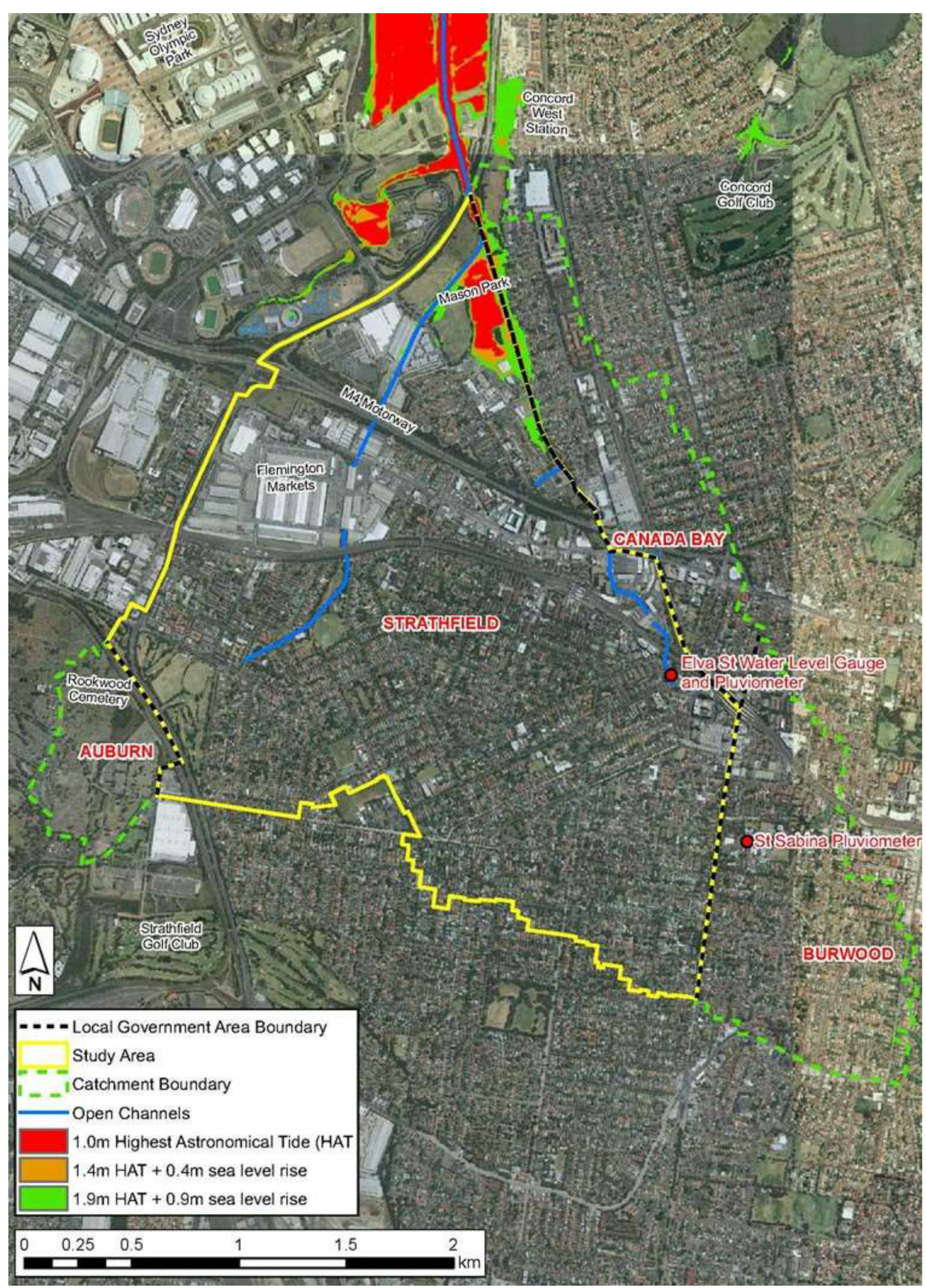

FIGURE 2 | Powells Creek catchment (after WMAwater, 2016). 
TABLE 1 | Land use in the Powells Creek catchment (after Meutia, 2002).

\begin{tabular}{|c|c|c|}
\hline Land use & Area (HA) & Proportion (\%) \\
\hline Residential & 504.7 & 60.0 \\
\hline Industrial & 40.5 & 4.8 \\
\hline Commercial & 27.1 & 3.2 \\
\hline Open space & 61.1 & 7.3 \\
\hline Special use & 208.1 & 24.7 \\
\hline
\end{tabular}

TABLE 2 | Calibration events.

\begin{tabular}{|c|c|c|c|c|c|}
\hline Date & Rainfall (mm) & Flow $\left(\mathrm{m}^{3} / \mathrm{s}\right)$ & Duration (hrs) & Rating table ${ }^{1}$ & Approximately $\mathrm{ARI}^{2}$ (years) \\
\hline March 1990 & 55.2 & 22.94 & 5 & Extrapolated & 47 \\
\hline November 1984 & 179.5 & 21.16 & 90 & Extrapolated & 21 \\
\hline March 1995 & 57.2 & 12.24 & 25 & Within & 4.3 \\
\hline October 1985 & 16.2 & 11.89 & 3 & Within & 3.9 \\
\hline January 1997 & 52.2 & 6.871 & 32 & Within & 1.5 \\
\hline October 1997 & 46.0 & 5.706 & 9 & Within & 1.2 \\
\hline
\end{tabular}

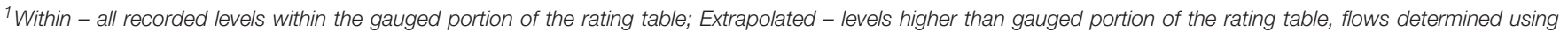
extrapolated relationship. ${ }^{2}$ Approximately ARI determined from Cunnane Plotting Position.

TABLE 3 | Parameter considered during model calibration.

\begin{tabular}{ll}
\hline Subcatchment parameter & Channel parameter \\
\hline Subcatchment width & \\
Subcatchment slope & \\
Imperviousness & Conduit roughness \\
Surface roughness (impervious and pervious) & \\
Depression storage (impervious and pervious) & \\
Impervious area with no depression storage & \\
Infiltration parameters (maximum rate, minimum & \\
rate, infiltration decay, and infiltration recovery rate) & \\
\hline
\end{tabular}

main open channel was established in 1892 (Meutia, 2002) and the closed pipe system was established in the 1920s.

Shown in Table $\mathbf{1}$ are the land-use classifications within the Powells Creek catchment as outlined by Meutia (2002). From a topographic perspective, the catchment is classified as having gentle slopes between 4 and 6\% with a maximum elevation of $40 \mathrm{~m} \mathrm{AHD}$; the minimum elevation is governed by the tidal regime of the Parramatta River.

\section{Available Data}

The School of Civil and Environmental Engineering at The University of New South Wales operated a gauging station on the main Powells Creek Stormwater Channel during the period 1958 to 2005. The location of this gauging station is shown in Figure 2. The catchment area draining to this gauging station consists of $2.3 \mathrm{~km}^{2}$ of the total $8.41 \mathrm{~km}^{2}$ catchment area. Initially this gauging station monitored only the flow quantity but since the early 1990s monitored water quality parameters as well.

Numerous stream gaugings have been taken at this gauging station to define the rating curve for translation of level to recorded flows. There are 14 gaugings below $0.5 \mathrm{~m}$ and 14 gaugings between 0.5 and $1.0 \mathrm{~m}$; the highest traditional gauging used in developing the rating curve was $1.35 \mathrm{~m}\left(13.8 \mathrm{~m}^{3} / \mathrm{s}\right)$. Gauging data above 1.35 to $1.65 \mathrm{~m}$ used the technique presented by Tilley et al. (2000) for gauging in rapidly varying flows; no gauge data is available above $1.65 \mathrm{~m}$ to validate the rating curve for the peak flood flows.

In addition to the flow data, continuous rainfall data was collected at two locations within the gauged portion of the catchment; these locations were at the centroid of the gauged catchment and at the flow gauging station. While this rainfall data was collected for the same period as the flow data, only rainfall data for the period 1981 to 1998 from the flow gauging station was available for this study.

TABLE 4 | Powells Creek calibration metrics.

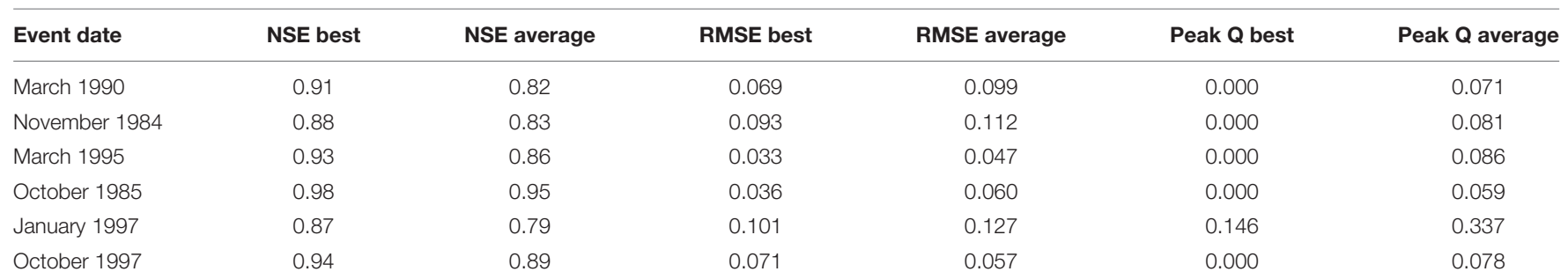




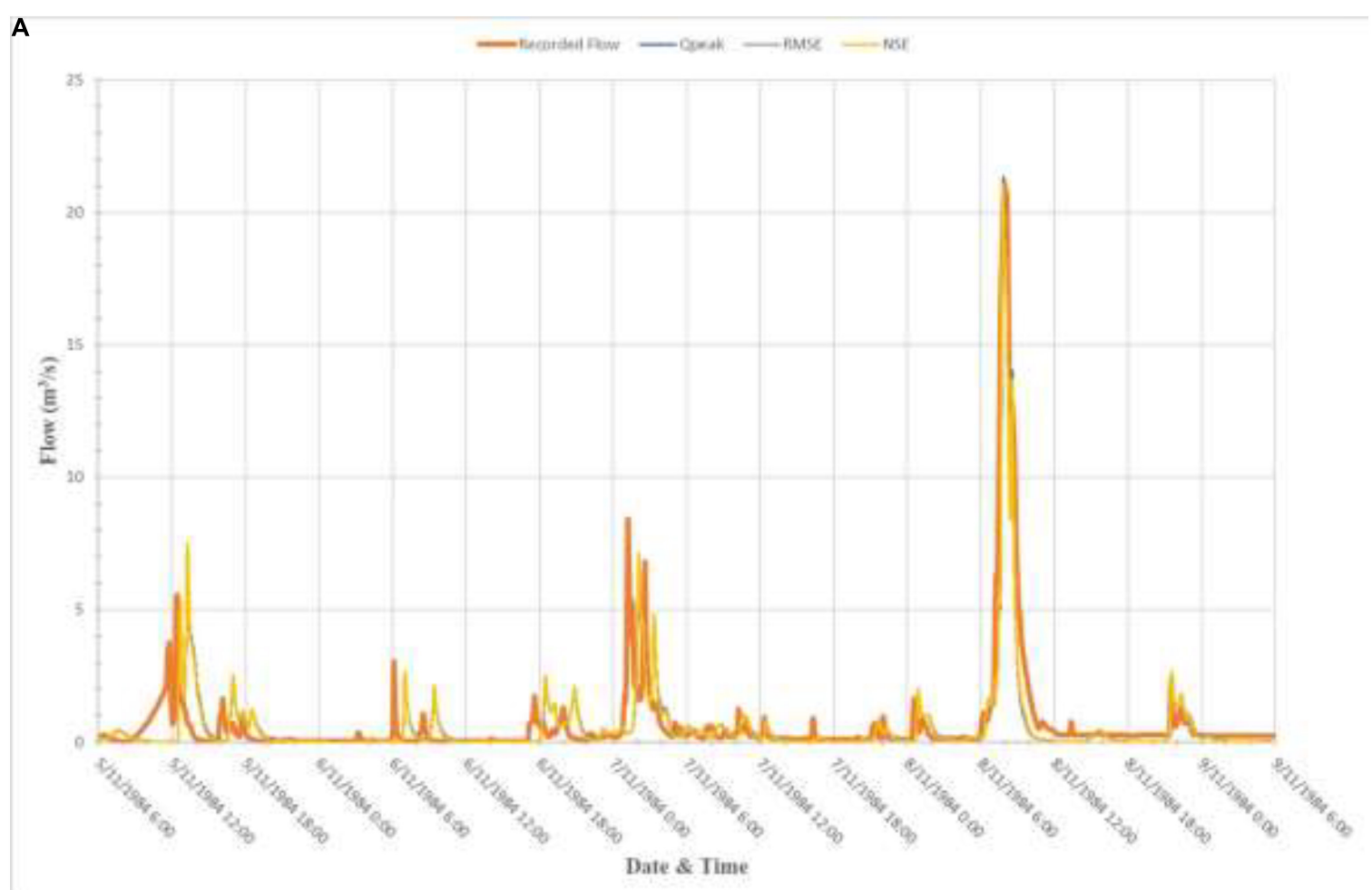

\section{November 1984}

B

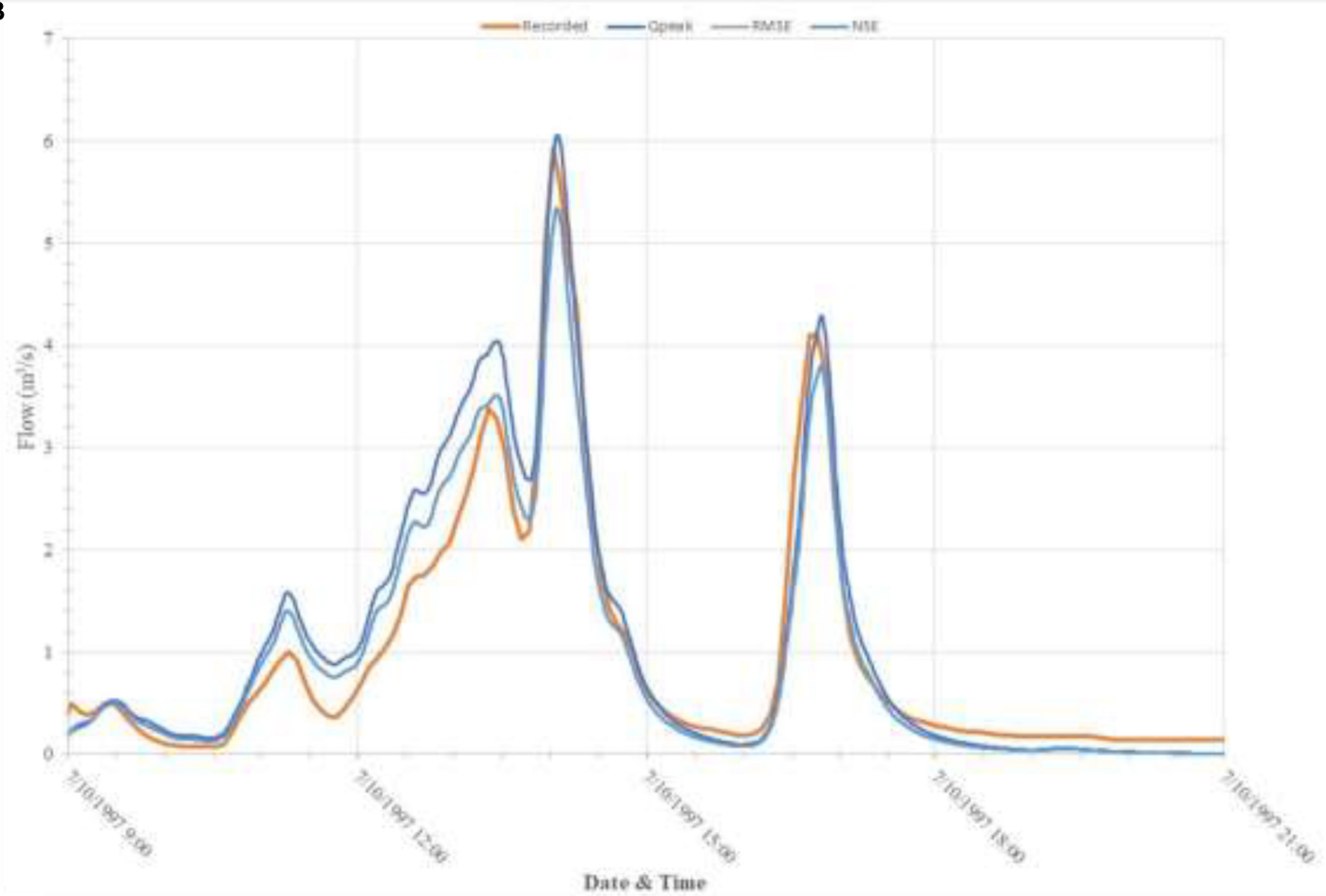

October 1997

FIGURE 3 | Predicted hydrographs for selected calibration events, (A) November 1984, (B) October 1997. 


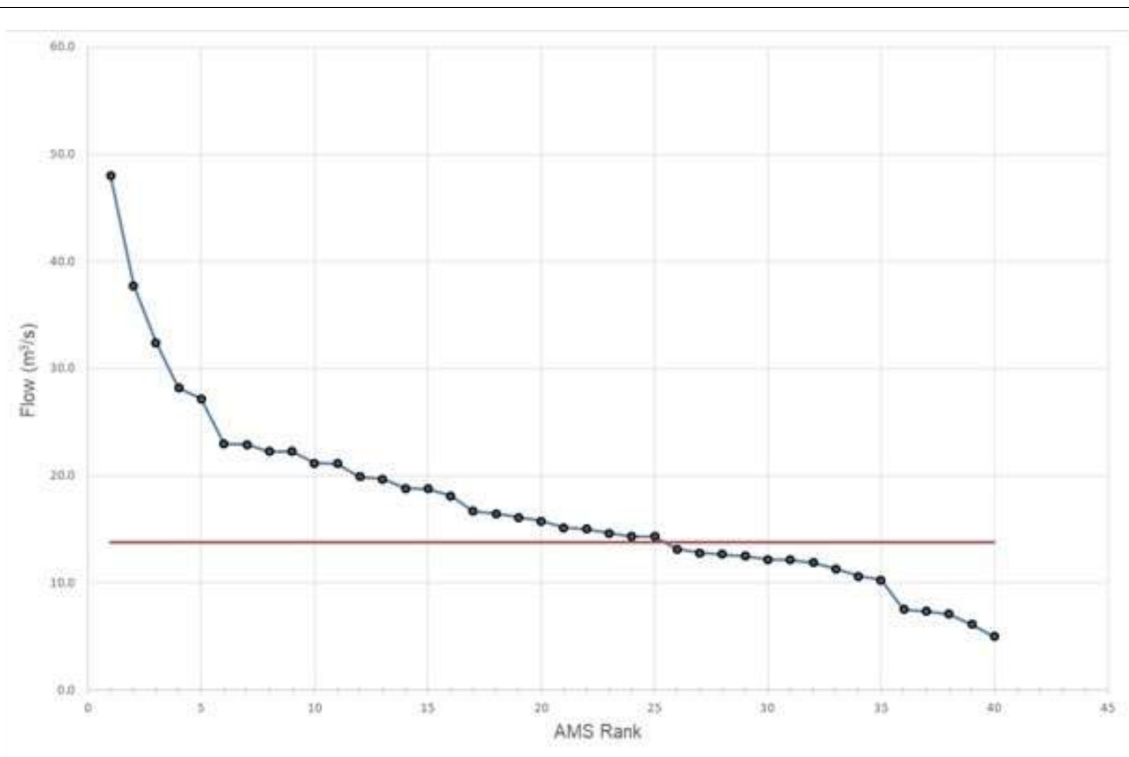

FIGURE 4 | Powells Creek ranked AMS.

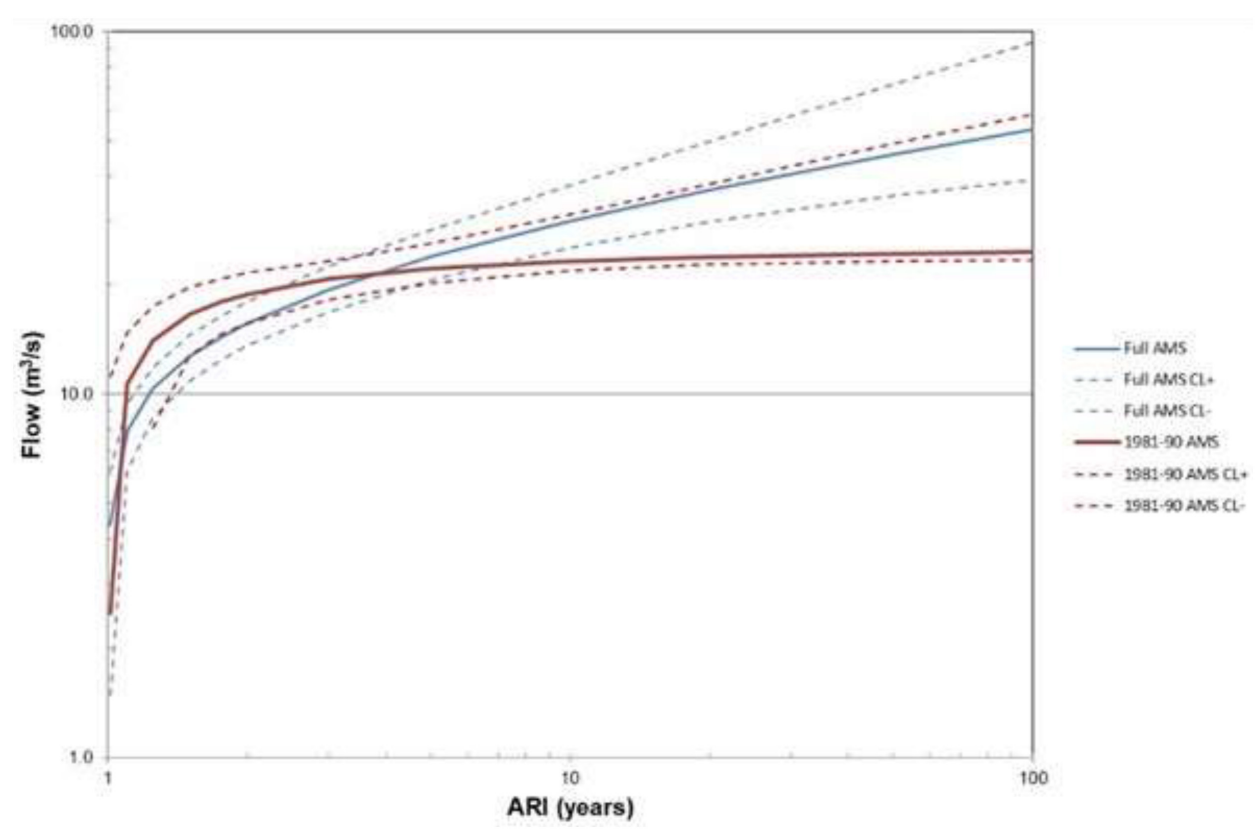

FIGURE 5 | Flood frequency for Powells Creek gauging station.

TABLE 5 | GEV parameters for annual maxima series of 40 and 10 years duration.

\begin{tabular}{|c|c|c|c|c|}
\hline Parameter & \multicolumn{2}{|c|}{40 YEAR AMS } & \multicolumn{2}{|c|}{10 YEAR AMS } \\
\hline Location & 2.747 & 0.076 & 17.126 & 2.118 \\
\hline $\log _{e}$ (Scale) & -0.731 & 0.113 & 1.686 & 0.363 \\
\hline Shape & -0.202 & 0.337 & 0.689 & 0.559 \\
\hline
\end{tabular}




\section{Deterministic Approach}

\begin{tabular}{|c|c|c|}
\hline $\begin{array}{l}\text { Design storm event: } \\
\text { - Probability ? }\end{array}$ & $\begin{array}{c}\text { Mathematical Model } \\
\text { of System }\end{array}$ & $\begin{array}{l}\text { Design Catchment } \\
\text { conditions: }\end{array}$ \\
\hline $\begin{array}{l}\text { - Rainfall intensity ? } \\
\text { - Storm duration? } \\
\text { - Temporal pattern? } \\
\text { - Dry period? }\end{array}$ & $\begin{array}{l}\text { Design Flood with } \\
\text { Unknown } \\
\text { Probability }\end{array}$ & $\begin{array}{l}\text { - Catchment wetness ? } \\
\text { - Catchment storages? } \\
\text { - Urbanisation? } \\
\text { - Time of Year? }\end{array}$ \\
\hline
\end{tabular}

\section{Probabilistic Approach}

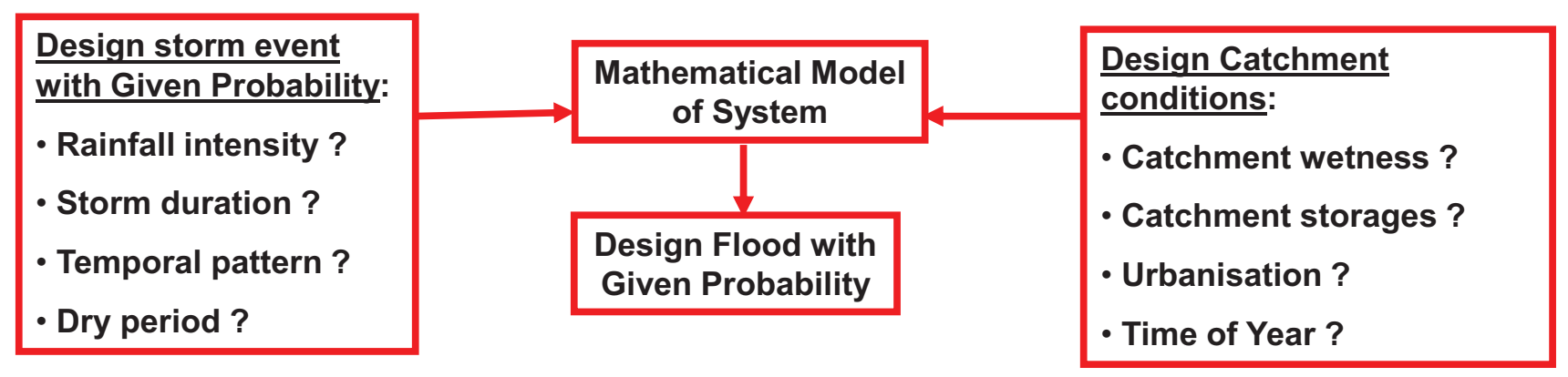

FIGURE 6 | Alternative conceptual usage of catchment models for flood risk assessment (after Ball, 2017).

Flow and rainfall data for individual events were extracted from this dataset for model calibration. Details of this data are presented in Table 2.

\section{Catchment Model}

There are numerous alternative software systems suitable for process-based modeling of existing and potential urban catchments. After considering these alternatives, the SWMM system (Rossman, 2005) was used herein for data generation. This model has received extensive application; see, for example, Leutnant et al. (2019) and Broekhuizen et al. (2020) for recent applications.

SWMM is a physically distributed catchment modeling system consistent with the conceptual components of a catchment modeling system proposed by Ball (1992); these components are:

- Generation - this component of the modeling system is concerned with spatial and temporal models necessary to convert point data into spatial-temporal data. An example is the conversion of point rainfall records into spatial rainfall models over the catchment at suitable resolution;

- Collection - the component of the model where those processes concerned with the generation of runoff are dominant. This is the hydrologic component of the modeling system;
- Transport - the component of the model where the processes concerned with the movement of water through the drainage system are dominant. This is the hydraulic component of the modeling system; and

- Disposal - the component of the modeling system concerned with the discharge of water from the drainage system into receiving waters.

For construction of the catchment model, the Powells Creek catchment was divided into 103 subcatchments and a similar number of channels. SWMM has the capacity for each subcatchment and channel to have unique parameter values. This capacity was utilized during calibration of the model.

There are many different parameters necessary for operation of a catchment modeling system; these parameters can be categorized arbitrarily into:

- Measured parameters. These are parameters that are physically measured such as pipe diameters, catchment areas, rainfall depth or rainfall intensity, etc.; and

- Inferred parameters. These are parameters that are not measured and are determined from the application of a model. Examples of inferred parameters are Manning's roughness for catchment surfaces or channels, depression storage, catchment or subcatchment imperviousness. 


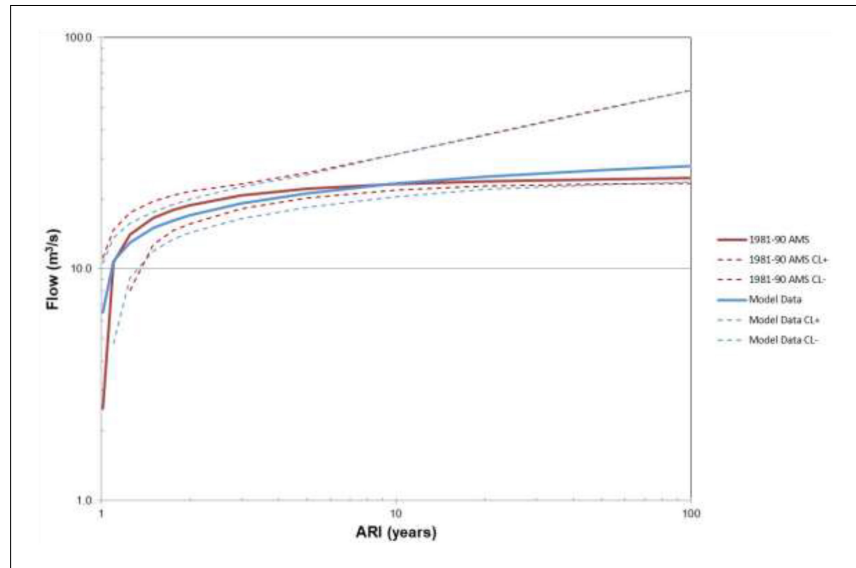

FIGURE 7 | Comparison of FFA from monitored and modeled data.

While the interface between these categories may appear as an absolute division, the interface between these categories is vague with parameters oscillating between the categories depending on the viewpoint of the user. For example, rainfall depth in the above discussion is defined as a measured parameter, but this measurement is only at the rainfall gauge itself with rainfall at other locations within the catchment (assuming the rain gauge is within the catchment) being inferred by application of a spatial rainfall model; see Ball and Luk (1998) for a discussion of the potential errors introduced through different inference models for the spatial distribution of rainfall over a catchment. Consideration of other parameters such as the catchment, or subcatchment, area also reveals a variability in measured parameters depending on, for example, the scale of the map from which the area was measured. In general, the values of inferred parameters are considered those that need to be adjusted during calibration, while measured parameters are assumed error free during the calibration process.

For the purposes of calibrating the Powells Creek model used in this study, the parameters considered are shown in Table 3. A previously calibrated model of Powells Creek was available from Meutia (2002). These parameter values were used as a search starting point for the most generic parameter values and their uncertainty. Initial feasible parameter values were defined as $\pm 50 \%$ of the values obtained by Meutia (2002); in other words, all parameter values tested were within $\pm 50 \%$ of the calibrated values obtained by Meutia (2002).

Previously Fang and Ball (2007) used a genetic algorithm (GA) to search the parameter space for feasible parameter sets within a
GLUE framework; a similar approach was used herein with a GA population of 1000. More details of the GA are presented by Fang and Ball (2007) and, hence, are not presented herein.

There are numerous alternative metrics that can be used to assess the suitability of the calibration obtained. Shown in Table $\mathbf{4}$ are the calibration metrics if Nash-Sutcliffe Efficiency (NSE), Root Mean Square Error (RMSE), and Peak Discharge $\left(\mathrm{Q}_{\text {peak }}\right)$ are used to assess the calibration. A visual comparison for some of the predicted hydrographs using the best parameter sets (i.e., the minimum error) for two events is shown in Figure 3. It should be noted that the best parameter set differed between events and between alternative calibration metrics.

\section{ANALYSIS OF FIELD DATA}

A common analysis approach for design flood estimation based on monitored data is the use of At-Site flood frequency analysis (FFA). While the period of record extended for 47 years, an annual maximum series (AMS) could be extracted only for a continuous 40 year period. Shown in Figure 4 is the ranked AMS. As can be seen from consideration of this figure, the highest 25 recorded flows are in the extrapolation zone of the rating curve; in other words, 25 of the AMS data points are above the highest validated point on the rating curve. This means that the Mean Annual Flood (Median of the AMS) lies within the extrapolation zone of the rating curve; note that the Mean Annual Flood is important for estimation of the value of the location parameter for most three parameter statistical models of the relationship between flood magnitude and likelihood.

Undertaking an FFA for this site using the full 40 year AMS in accordance with guidance presented in Australian Rainfall and Runoff (Ball et al., 2016) results in the flood frequency shown in Figure 5. In this case, the three parameter GEV distribution was fitted to the 40 available data points. Shown in Table 5 are the estimated values for these parameters together with their estimated variability.

Also shown in Figure $\mathbf{5}$ and Table $\mathbf{5}$ are the flood frequency predictions and the relevant statistical model parameters if the 10-year period, 1981-1990, were used in lieu of the full period of record. As can be seen in Figure 4 and as suggested by the values presented in Table 2 , there are considerable differences in the predicted relationships even though the shorter period AMS occurs within the period of the longer AMS. This highlights the need, when assessing flood frequency relationships, to ensure consistency of data sources and periods.

TABLE 6 | FFA parameters for 10 year AMS

\begin{tabular}{lccrc}
\hline Parameter & \multicolumn{2}{c}{ Monitored data } & \multicolumn{2}{c}{ Modeled data } \\
\cline { 2 - 5 } & Most probable value & SD & Most probable value \\
\hline Location & 17.13 & 2.12 & 15.47 & 1.73 \\
Loge $_{e}$ (Scale) & 1.69 & 0.36 & 0.30 \\
Shape & 0.69 & 0.56 & 0.27
\end{tabular}




\section{ANALYSIS OF MODELED DATA}

As noted earlier, the aim of most physically based catchment models is the reproduction of the data that would have been recorded if monitoring were being undertaken at that location for the desired catchment conditions and climate state. While generation of both continuous and event specific data is feasible, for purposes of generating data for prediction of flood risk, techniques considering a single burst (or event) have been the more popular.

When catchment modeling using a single event or burst approach is employed, there are two alternative interpretations, namely AEP neutrality and event reproduction. These alternatives are shown in Figure 6.

Where the single burst approach has been implemented with the assumption that the frequency of the rainfall is transformed to the frequency of the resultant flood characteristic, it can be argued that the approach is a Regional Flood Frequency Estimation technique; in other words, the catchment model is used to provide a regression ensuring consideration of the main catchment factors. An example of this approach is provided by Hill et al. (1998) who developed a method of estimating loss model parameters that are likely to result in the frequency of the rainfall being transferred to the frequency of the design flood flow.

It is possible to use a single event or burst approach without the assumption of AEP neutrality. In these circumstances, the catchment model is used to analyze the catchment response to a design rainfall event with the probability of the resultant flood characteristics being unknown.

The alternative to simulation of single events is continuous simulation resulting in continuous time series data; to estimate the flood risk, it is necessary to analyze this data using Flood Frequency. Previously, the calibration of the SWMM model to individual events was discussed. Since the focus of the data generation is the estimation of the flood risk, successful prediction of higher flows and flow depths was required and lower flows that were not likely to influence the statistical analysis did not need similar prediction reliability. Hence, the parameter sets derived from the event calibration were employed in the generation of the continuous time series data.

The model generated time series data were analyzed in a similar manner to the field monitored data to develop a flood hazard magnitude likelihood relationship. Shown in Figure 7

\section{REFERENCES}

Andimuthu, R., Kandasamy, P., Mudgal, B. V., Jeganathan, A., Balu, A., and Sankar, G. (2019). Performance of urban storm drainage network under changing climate scenarios: flood mitigation in Indian coastal city. Sci. Rep. 9:7783. doi: 10.1038/s41598-019-43859-3

Audisio, C., and Turconi, L. (2011). Urban floods: a case study in the Savigliano area (North-Western Italy). Nat. Hazards Earth Syst. Sci. 11, 2951-2964. doi: 10.5194/nhess-11-2951-2011

Ball, J. E. (1992). A Review of Numerical Models for Prediction of Catchment Water Quantity and Quality. Research Report No. 180, Water Research Laboratory, Dept. of Water Engineering, School of Civil Engineering. Sydney: The University of New South Wales. is a graphical representation of this relationship. Also shown in this figure is the same relationship developed from the field monitored data for the same period of record. Inspection of this figure suggests a visual similarity of the two relationships. This similarity of relationship is confirmed if the parameters for the GEV relationship, shown in Table 6, are considered.

\section{CONCLUSION}

Management of floods in urban catchments is a complex task. Data for this management task can come from a variety of sources, namely monitoring and modeling of the catchment. Catchment modeling here refers to modeling aimed at reproducing data that would have been recorded if field monitoring were undertaken at that location for that catchment condition and rainfall record; many catchment modeling approaches do not meet this definition as the models are used in a statistical context rather than a physical process context. Management of data from both sources requires definition of the metadata about the data to enable assessment of data uncertainty and to enable appropriate data mining to determine flood risk. Finally, using the Powells Creek catchment in Sydney, Australia as a case study, it was shown that design flood predictions from data mining of both field monitored and model generated data were similar provided consistent periods of record were utilized for the same catchment conditions; in other words, the rain records and catchment conditions were from the same period.

\section{DATA AVAILABILITY STATEMENT}

The datasets generated for this study are available on request to the corresponding author.

\section{AUTHOR CONTRIBUTIONS}

JB made substantial contributions to the conception, design of the work; drafted the work for important intellectual content; provided approval for publication of the content; and agrees to be accountable for all aspects of the work in ensuring that questions related to the accuracy or integrity of any part of the work are appropriately investigated and resolved.

Ball, J. E. (2014). "Flood estimation under changing climates," in Proeedings of the. 2014 IAHR-APD Congress, Hanoi.

Ball, J. E. (2017). “Urban Flood Modelling - Process or Regression," in Proceedings $37^{\text {th }}$ IAHR World Congress, Kuala Lumpur, Malaysia.

Ball, J. E. (2018). "A classic hydroinformatic problem - floods," in Proceedings of the 2018 International Conference on Hydroinformatics, Palermo.

Ball, J. E., and Luk, K. C. (1998). Modelling the spatial variability of rainfall over a catchment. ASCE J. Hydrol. Eng. 3, 122-130.

Ball, J. E., Babister, M., Nathan, R., Weeks, W., Weinmann, E., Retallick, M., et al. (2016). Australian Rainfall and Runoff: A Guide to Flood Estimation. Canberra: Commonwealth of Australia.

Broekhuizen, I., Leonhardt, G., Marsalek, J., and Viklander, M. (2020). Event selection and two-stage approach for calibrating models of green urban 
drainage systems. Hydrol. Earth Syst. Sci. 24, 869-885. doi: 10.5194/hess-24869-2020

Fang, T., and Ball, J. E. (2007). Evaluation of spatially variable control parameters in a complex catchment modelling system: a genetic algorithm application. J. Hydroinform. 9, 163-173. doi: 10.2166/hydro. 2007.026

Hettiarachchi, S., Wasko, C., and Sharma, A. (2018). Increase in flood risk resulting from climate change in a developed urban watershed - the role of storm temporal patterns. Hydrol. Earth Syst. Sci. 22, 2041-2056. doi: 10.5194/hess22-2041-2018

Hill, P. I., Mein, R. G., and Siriwardena, L. (1998). How Much Rainfall Becomes Runoff? - Loss Modelling for Flood Estimation. Industry Report 98/5, Cooperative Research Centre for Catchment Hydrology. Clayton: Monash University.

Leutnant, D., Döring, A., and Uhl, M. (2019). swmmr - an R package to interface SWMM. Urban Water J. 16, 68-76. doi: 10.1080/1573062X.2019. 1611889

Meutia, E. Z. (2002). Development of a Catchment Modelling System for the Powells Creek Catchment. Unpublished Master of Engineering Science Report, The University of New South Wales, Sydney.
Rossman, L. A. (2005). Storm Water Management Model - User's Manual, Version 5.0. Report EPA/600/R-05/040. Cincinnati: U.S. Environmental Protection Agency.

Smithers, J. C. (2012). Methods for design flood estimation in South Africa. Water SA 38, 633-646. doi: 10.4314/wsa.v38i4.19

Tilley, J. H., Coates, A., Wojcik, A., Ball, J. E., and Abustan, I. (2000). Development of a stage-discharge relationship for rapidly varying flows in urban streams. Austral. J. Water Resour. 4, 139-145.

WMAwater. (2016). Powells Creek and Saleyards Creek Revised Flood Study. Unpublished Report. Sydney, Australia: Strathfield Municipal Council.

Conflict of Interest: The author declares that the research was conducted in the absence of any commercial or financial relationships that could be construed as a potential conflict of interest.

Copyright $\odot 2020$ Ball. This is an open-access article distributed under the terms of the Creative Commons Attribution License (CC BY). The use, distribution or reproduction in other forums is permitted, provided the original author(s) and the copyright owner(s) are credited and that the original publication in this journal is cited, in accordance with accepted academic practice. No use, distribution or reproduction is permitted which does not comply with these terms. 